This item was submitted to Loughborough's Research Repository by the author.

Items in Figshare are protected by copyright, with all rights reserved, unless otherwise indicated.

\title{
Problem structuring methods as intervention tools: reflections from their use
} with multi-organisational teams

PLEASE CITE THE PUBLISHED VERSION

http://dx.doi.org/10.1016/j.omega.2006.08.001

PUBLISHER

(C) Elsevier

VERSION

AM (Accepted Manuscript)

LICENCE

CC BY-NC-ND 4.0

REPOSITORY RECORD

Franco, L. Alberto. 2019. "Problem Structuring Methods as Intervention Tools: Reflections from Their Use with Multi-organisational Teams". figshare. https://hdl.handle.net/2134/14641. 
This item was submitted to Loughborough's Institutional Repository (https://dspace.lboro.ac.uk/) by the author and is made available under the following Creative Commons Licence conditions.

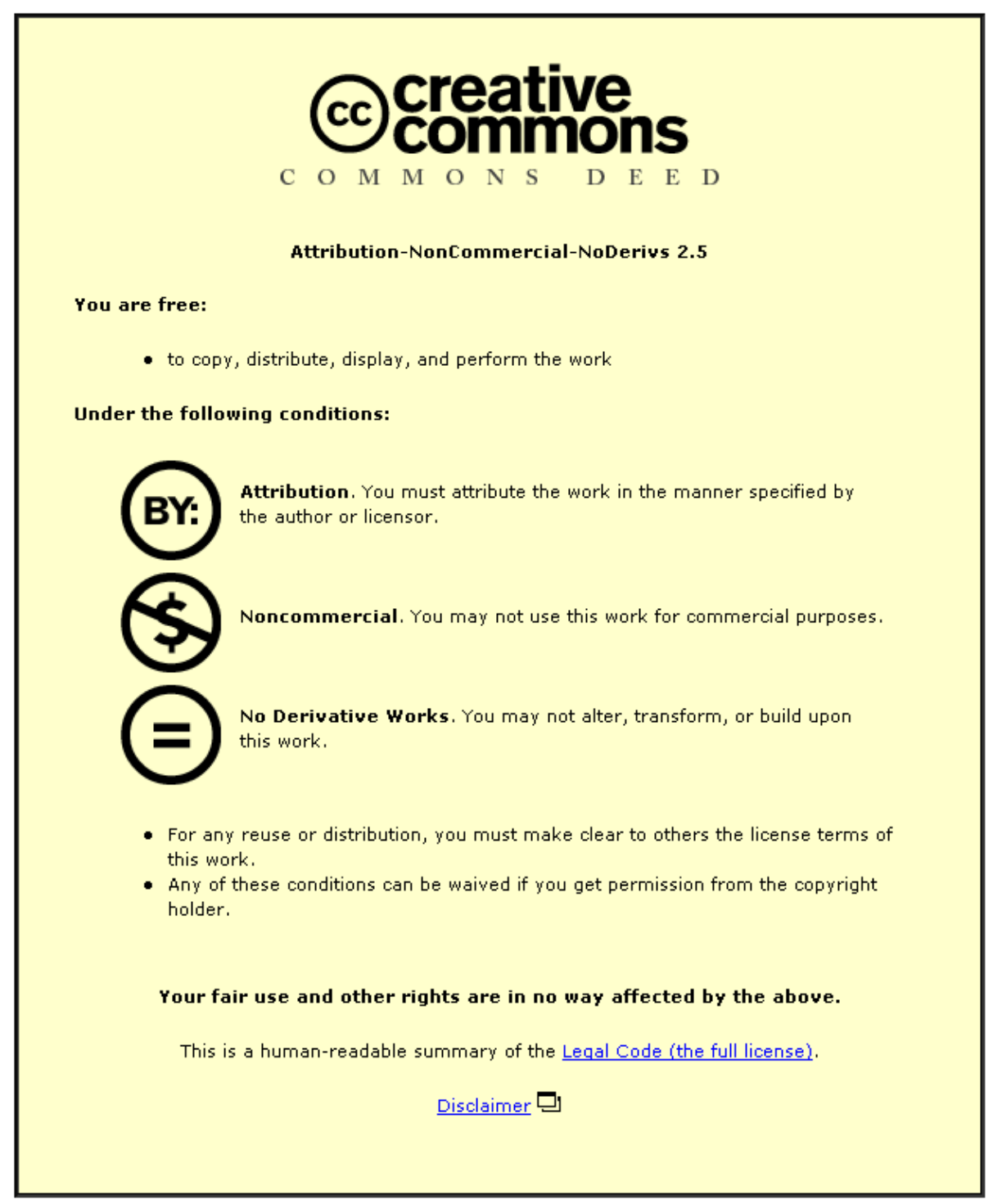

For the full text of this licence, please go to: http://creativecommons.org/licenses/by-nc-nd/2.5/ 


\title{
Problem Structuring Methods as Intervention Tools: reflections from their use with multi-organisational teams
}

\author{
L. Alberto Franco ${ }^{1}$ \\ Warwick Business School, University of Warwick CV4 7AL, UK
}

Problem structuring methods (PSMs), also known as soft OR approaches, are most commonly employed with teams formed by members who tend to operate within an overall framework of authority and accountability, and most of whom have the 'power to act' on their recommendations. However, other PSM users include teams whose members are drawn from different organisational settings to work on a problem of common interest. The multi-organisational nature of such multi-organisational teams (MOTs) adds further complexity to the PSM modelling and facilitation processes by increasing the potential for conflict regarding the problem. In addition, members of MOTs tend not to operate within an overall framework of authority and accountability and, therefore, do not necessarily have full authority to commit themselves to their joint agreements. This paper reports on the design and application of a PSM-based methodology with three such groups, within the context of a multi-organisational collaboration in the UK construction industry. The paper reflects on the apparent success of the intervention, discusses the appropriateness of PSMs in this particular intervention context, as well as the generalisibility of the findings to other PSMs and/or multi-organisational contexts. Directions for the research and practice of PSMs with MOTs are also presented.

\section{ABSTRACT}

Keywords: problem structuring methods, organisational intervention, multiorganisational teams, group decisions and negotiation.

\footnotetext{
${ }^{1}$ Email: alberto.franco@warwick.ac.uk

Tel.: +44 (0)2476 524691

Fax: +44 (0)2476 54539
} 


\section{Introduction}

Problem structuring methods (PSMs) are a family of 'soft' operational research methods aimed at assisting groups in tackling a complex problem area of common interest [1]. PSMs handle such problematic situations through group modelling and facilitation, with a view to generating consensus on problem structure, and usually, on initial commitments to consequential action [1]. Examples of well-established PSMs include: Strategic Options Analysis and Development (SODA) [2], Soft Systems Methodology (SSM) [3], the Strategic Choice Approach (SCA) [4], Drama Theory [5], Group Model Building [6], and Decision Conferencing [7].

The typical user of PSMs have been top management teams working on ill-defined strategic situations characterised by high levels of complexity, uncertainty, and sometimes conflict [1]. Members of such teams tend to operate within a single framework of authority and accountability, and most have the 'power to act' and commit themselves to whatever conclusions might have been arrived at during their meetings [e.g. 8].

There is, however, other type of PSM user whose characteristics are in sharp contrast with those exhibited by top management teams. Such teams are multi-organisational in nature, their members usually drawn from a wide variety of stakeholder organisations with diverse goals, values and working practices, and whose main purpose is to work together to resolve complex issues of common concern, and which no single organisation can resolve unilaterally without collaborating [9-12] A direct consequence of the multi-organisational nature of such teams is that further complexity is added to the PSM intervention process because the potential for conflict regarding multiple beliefs and values associated with the problem is increased [13-15]

In addition, and contrary to top management teams, multi-organisational teams (MOTs) do not exhibit an overall framework of authority and power [10, 13], and are more likely to have different degrees of accountability to outside interests. This means that MOT members will not necessarily have full authority to commit their own organisations to the products of their joint decision-making $[16,17]$. As a result, MOT members have to engage in the legitimation of their joint commitments within their own organisational constituencies before actual implementation takes place. Such legitimation attempts will require MOT members working as competent 'boundary spanners' within and across organisations $[16,18]$.

Most of what has been reported about PSMs in the OR literature has focused on management teams operating within single organisations. However, published studies on the use of PSMs with MOTs are increasing [e.g. 10, 12, 19-21]. This paper makes a further contribution to this emergent body of PSM research and practice by reporting and reflecting on an intervention that used a modified version of the Strategic Choice Approach (SCA) [4]. The aim of the paper is thus to increase our understanding and use of PSMs as organisational intervention tools, with particular reference to the MOT context.

The paper is structured as follows. The next section provides contextual information of the intervention. The following sections describe the intervention design and 
application of a modified version of SCA with three MOTs drawn from a UK construction partnership. The subsequent section then presents and discusses the evaluation of the PSM intervention from the participants' perspective. This is followed by a discussion on the significance of the experience and its implications for the research and practice of PSMs within multi-organisational contexts. The final section identifies future research directions.

\section{The intervention context}

The intervention reported here was carried out during 1997-1999 in a major company operating in the leisure sector (LeisureCo - a pseudonym), as part of a larger action research programme in the UK construction industry [for further information about this research programme, see 22]. At the time of the research, LeisureCo were engaged in a series of refurbishment projects of their hotels to meet the standards of their recently acquired American four-star hotel franchise, as well as in building new hotels. This construction work was taking place within a then recently established collaborative partnership between LeisureCo and their major contractors and subcontractors, led by LeisureCo. This move reflected a bigger move within the whole UK construction industry from traditional contractual arrangements towards more collaborative ways of working [19, 23, 24].

The LeisureCo partnership was entered with great expectations by the partners. For LeisureCo, partnering was seen as a way to reduce uncertainty about the product. LeisureCo wanted to move away from a traditional tendering process in which the least costly tender was likely to be favoured by them, but where the quality of the final product was not always warranted. The LeisureCo partners also saw the partnering relationship as a means to reduce uncertainty. In their case, however, the benefit of uncertainty reduction would lie in ensuring steady future work through a continuing partnering relationship.

To demonstrate their commitment to developing a trusting relationship with their partners, LeisureCo moved away from traditional written contracts and fully documented project specifications. This move meant that both project specifications and partnership roles and responsibilities were initially ill-defined. At the operational level, the main interface between LeisureCo and their partners was the (construction) project teams. These teams would have regular meetings to review project progress. At the more strategic level, LeisureCo had separate periodical meetings with representatives of their partner contractors, partner project managers, and partner quantity surveyors respectively. These meetings were aimed at reviewing both the projects and the partnering process. No forums for cross-discipline partner meetings at the strategic level were in place during the projects.

Overall, the partners' high expectations, the ill-definition of the project brief and of roles and responsibilities, and the lack of cross-organisational interfaces, comprised a set of initial conditions which had a significant impact on the nature of the subsequent interactions between all partners, and on their learning about how the partnership operation was developing. First, because the different partnership teams entered their projects with very broad project specifications, critical aspects of the project task such as, for example, bedroom model documents, were ill-defined and open to multiple 
interpretations, and kept changing throughout the projects. As a result, communications between LeisureCo and their partners were extremely difficult.

Second, the partnership interfaces did not allow for interdependencies to be adequately managed between the partners. Reducing the chances of unclear and changing project specifications would have required the involvement of all partners at the briefing stage of a project. However, the LeisureCo partners did not have any involvement during this stage. Instead, LeisureCo had their own LeisureCo-only design committee in charge of decisions about design both as it related to the franchiser and to the products which were to be sold in the market (e.g. a hotel bedroom, a hotel restaurant, etc.). Indeed, the relationship with the franchiser was still, at the time of the research intervention, an evolving one.

As the relationship between franchiser and franchisee was a new and evolving one, LeisureCo were having difficulties in understanding the requirements of the former, which meant that they were unable to sign off their designs and send the relevant information to their partners on a timely basis. In other words, LeisureCo were too far apart in their ways of doing things to understand their partners' needs and connect to and communicate with their partners effectively.

The problems caused by ill-defined and changing project specifications were exacerbated by the lack of a clear definition of partnership roles and responsibilities. Early in the partnership it became apparent that some aspects of the partnership arrangements were causing difficulties to the partners. For example, in the initial partnership set-up, architects and designers were subcontracted by the partner contractors. This meant that both architects and designers had limited flexibility to operate and respond to LeisureCo's demands, which caused much frustration to all parties. In addition, in the initial partnership set-up the contractors had the responsibility to manage LeisureCo's preferred suppliers (called 'directs'), but the latter's payment came from LeisureCo. This meant that the contractors had little power to manage third party performance which significantly affected the contractor's responsiveness to the demands of LeisureCo.

Third, expectations between the partners suffered. Each partner entered the partnership with a set of explicit expectations. Some of these expectations stemmed from the industry context they entered the partnership from. Each partner also had expectations about the behaviours of the other partners, and used their interactions with each other as a way to gather clues to validate or challenge initial expectations. For example, partner contractors started to raise concerns about LeisureCo's inability to recognize the efforts over the projects in agreeing the level of return achieved by the contractors.

Fourth, as their interactions unfolded and the partners became aware of discrepancies from expected processes, the partners learned about each other, and about each others' organizational routines. In the case of the LeisureCo partners, as they discovered the demands of the project tasks and LeisureCo's ways of working, they questioned LeisureCo's ability to work sufficiently closely with them to perform the project tasks successfully. 
In summary, the ill-definition and changing nature of the project task, the lack of clear partnership roles and responsibilities, together with the slow and inefficient response by LeisureCo to the need of their partners for effective coordination led to mixed evaluations of the partnership relationship, and to a recognition of the need for jointly reviewing both the projects and the partnership process.

\section{Designing the intervention}

A formal reviewing mechanism for construction projects was developed and implemented within the LeisureCo partnership [the reviewing mechanism is discussed in 19]. The developed methodology was based on the Strategic Choice Approach (SCA) [4], a particular problem structuring method, and designed both to focus on the key issues faced by members of a construction project team, and as the basis for a generic project review processes.

The SCA-based methodology was used by three multi-organisational teams, drawn from LeisureCo's pool of partnership projects, to carry out a post-completion review of their projects. The three SCA workshops involved the review of two redevelopment projects and a design and build project. Each of the workshops comprised seven to nine participants representing a variety of stakeholders including the LeisureCo's property division and operational management, the main contractor, project management consultants, quantity surveyors, architects and designers, but did not include specialist trade contractors who were not part of the partnering arrangements. As the partnership involved a number of companies for each specialty, a different set of companies was involved in each workshop and only one company other than LeisureCo was involved in more than one workshop.

All workshops were held at, or close to, the project site and carried out in a 5-hour session. The format of the discussions was similar to that associated with a typical PSM workshop. That is, they were facilitated and the room was arranged in a horseshoe layout without tables. Previous to each workshop, information about the project was collated through the gathering of participants' answers to a pre-workshop questionnaire (for a sample of this questionnaire, see [19]). The purpose of this questionnaire was to allow the author to build a draft 'project review profile' and to formulate preliminary decision areas. This profile and suggestions of key decision areas were circulated to participants before the workshops. Furthermore, as the time available for workshops was limited, the pre-workshop questionnaire helped in collecting information that would otherwise have required a whole session at the workshops, which was not possible. Indeed, it was clear from the outset that given the limited duration of the planned workshops, they would need to focus on the generation of outputs where the most progress could be made.

It has been argued that the PSM modeller/facilitator working with MOTs must be seen as 'legitimate' by MOT members [10, 13]. For these reasons, it was agreed that a LeisureCo representative (an experienced facilitator) was going to facilitate the PSM workshops. This meant that it was important that the LeisureCo representative became familiar and comfortable with the method and the terminology used. When the author first discussed the basic ideas of SCA with the LeisureCo facilitator, he then expressed his worries over the complexity of the methods and the language used, 
which he thought might not be welcomed by the workshop participants. As a result, the author produced an adapted, shortened version of SCA, where the method's working modes of 'shaping', 'designing', 'comparing' and 'choosing' were followed loosely, and alternative common language explanations of its terms was provided to avoid confusion. This shorter version also included an opening session focusing on 'project victories' as a means to both build confidence among workshop participants, and recognise that all construction projects have elements of successes to be learned from as well as outstanding issues. (The modified SCA method can be downloaded from http://www2.warwick.ac.uk/fac/soc/wbs/subjects/oris/modifiedsca.pdf.)

\section{The PSM workshops}

The first use of the adapted SCA method took place during the post-completion review of a hotel \& country club re-development project. At the beginning of the workshop, the facilitator started by explaining what it was hoped to have achieved by the end of the workshop. After these introductory remarks, and following the modified version of SCA, the project victories were considered first. Next, the draft candidate decision areas which had emerged from the pre-workshop questionnaire results were presented and the workshop participants were asked to comment on them so that they could be validated. The candidate decision areas had been written on postit notes placed on a flip chart, which allowed for easy modification of concepts by participants, and for patterns, relationships and overlaps to be adjusted and displayed by positioning and linking. Also, the seating arrangements made it easy for the participants to post their own ideas and take an active part in what roughly corresponded to the shaping stage of SCA.

There was general consensus between the workshop participants about the areas where decisions needed to be made. The development of an effective and efficient briefing process was the main concern. This area was seen as strategic and crucial for the success of the partnership. During the workshop, the discussion moved away from strategic issues and concentrated on operational aspects of the re-development project. In particular, 'snags' (i.e. defects in the resulting product) was specified as the most urgent area to address. This area represented an operational issue related to the handover of the project which the hotel operator was most concerned about. Indeed, post-workshop interviews confirmed that the hotel operators were mainly concerned with discussing the operational issues affecting a project handover. This was in stark contrast to the views of the other workshop participants, who were mostly interested on addressing strategic issues affecting the LeisureCo partnership.

During the latter part of the workshop, participants engaged in the development and prioritisation of options for action which roughly corresponds to the designing and comparing modes of SCA. Participants identified options within each of the two key decision areas (i.e. 'brief' and 'snagging'), and were encouraged by the facilitator to focus on options which they could effectively act upon. All the options surfaced were then discussed within the group to compare and evaluate in terms of their feasibility and consequences. Uncertainties were considered in the discussion although they were not explicitly articulated as such by the participants or the facilitator. 
All participants voiced their opinions and concerns about the options surfaced. This discussion gave rise to agreements regarding actions to be implemented, together with their responsible actors and tentative deadlines. Following the workshop event, communications between LeisureCo and the author confirmed that all the agreed actions regarding the outstanding snagging issues of the project, together with those related to the development of a new generic snagging process for all partnership projects, had been implemented within a two-week period.

The second use of SCA was during the post-completion review of the re-development project of another hotel \& country club, which took place shortly after the first workshop. This re-development project was considered a 'problematic' experience by the partners, and workshop participants showed willingness to reflect on and learn from the experience for the future benefit of the partnership.

The workshop format followed was similar to that used at the first workshop. Participants were informed that some of the candidate decision areas which had emerged from the pre-workshop questionnaire results paralleled those which had been identified in the first workshop (for example, the area of 'snagging' had resurfaced). Consequently, and in order to gain maximum benefit for the partnership from the intervention, participants decided that the focus of the second workshop should be on decision areas not previously addressed and at the strategic, rather than operational, level. This particular focus was facilitated by the review taking place nearly six months after completion, so that operational issues were by then less salient.

The facilitator of the second workshop was the same as before, and on this occasion he had become more acquainted with the SCA method and thus was able to use the method with more confidence than before, as well as to make clear distinctions between decision areas, different types of uncertainties, and comparison areas during the discussion at the workshop.

Developing the right level of detail in the project brief was the main concern expressed by participants. Three aspects related to this preoccupation were the management of the interface between LeisureCo and LeisureCo partners, the access to information about existing operating hotels, and the knowledge and communication of roles and responsibilities within the partnership. These issues represented interrelated areas for choice. For example, any choices regarding the level of detail in the project brief were perceived to have an impact on the choices available for the management of the interface between LeisureCo and LeisureCo partners.

Some of the agreements reached by participants in the second workshop involved immediate actions; whereas others comprised actions of the exploratory type. This difference may have resulted, as previously mentioned, from the facilitator's greater familiarity with the processes, techniques and tools of SCA.

Finally, the last use of SCA was during the post-completion review of a design and build project for a new hotel in London. On this occasion the main focus of the workshop was on developing improved ways of managing project changes. This focus can be explained by the fact that the new hotel represented a particularly complex and expensive venture for LeisureCo, a scale of project which they had never attempted before. In addition, the area of partnership development, identified as a decision area 
at the first workshop, was revisited. Post-workshop interviews indicated that the discussions held in the third workshop triggered a subsequent LeisureCo-led strategic review of the whole partnership processes and agreement.

\section{Participants' evaluation}

Multiple, tape-recorded, semi-structured interviews were conducted with the workshop participants. The average interview lasted between 60 and 90 minutes, and the focus of the interviews was on trying to understand as fully as possible participants' perceptions of the usefulness of the SCA-based methodology, as well as the events within and around the LeisureCo partnership and the perceptions of the participants about these events. All this information provided a rich data base with which to examine the impact of the PSM methodology with multi-organisational teams in a collaboration context such as the LeisureCo partnership. Analysis of the interview data was based on a grounded theory approach $[25,26]$ supported by the use of Atlas.ti software [27].

A number of themes emerged from the analysis of the data. First, workshop participants expressed the unanimous view that SCA was a transparent mechanism which helped them to understand each other, and to structure, clarify and learn about the issues confronting them. This was because they were able to share and crosspollinate their different perspectives, identify and understand the relationships between the different issues and areas for choice, and obtain a broader picture of the problems confronting the partnership. Most participants described the representation, structuring and prioritization of the issues as transparent, flexible, and efficient,

Second, all participants stated that SCA allowed them to openly discuss and jointly examine the issues affecting them, and that it was the openness forced upon participants by SCA which reduced opportunities for deliberate manipulation during their discussions, and significantly contributed to the high levels of supportability and ownership of the commitments achieved during the workshops. Participants also expressed that the discussion format and workshop layout reduced the chances of them 'taking positions' during the reviews. Typically, construction project meetings are driven by highly structured agendas and are led by the project manager. They are held around a table with each participant having a large number of papers in front of them, but each agenda item typically only involves two or three of the people present. Participants stated that the SCA discussion format made them felt comfortable to become involved and express their views freely. In addition, they observed their views being taken into account and adding to the richness of the discussions. Table 1 below shows a sample of coded excerpts from the interview transcripts.

\section{TABLE 1 ABOUT HERE}

Finally, those participants whose role within the LeisureCo partnership was strategic rather than operational (i.e. those who were not part of the project teams dealing with the day-to-day management of the projects) indicated that they had learned both from each other and from the projects, and that this learning was a key trigger for the actions that followed. The following examples illustrate the extent to which the learning achieved with SCA was disseminated to other projects within the partnership. 
A £4.6 million, 64-bedroom extension at a LeisureCo hotel in Edinburgh was planned to start in January 1999. Participating in this project were LeisureCo and one of their major contractors, who had taken part in one of the SCA workshops. Interviewed by the researcher, representatives of both organizations expressed that what they had learned at the SCA workshop review was subsequently applied to the planning of this new project, even though there were no specific actions for the new project resulting from the review. Moreover, the same SCA workshop format used in the reviews was again used at a phased review of a new LeisureCo hotel in Glasgow, and facilitated by the LeisureCo representative who had participated in one of the SCA reviews. This occurred without any prompting or supervision from the author. These examples illustrate that the partners had a strong ownership of the processes and products of the SCA intervention, saw the method's usefulness, and applied what they had learned.

Following each of the three SCA reviewing workshops, adjustments in the LeisureCo partnership relationship ensued. An emerging theme identified in the interview data suggests that after the SCA-supported reviews LeisureCo and their partners had developed heightened expectations. The evidence suggests that the reviewing mechanism appear to have contributed to a significant change in the nature of the partners' relations. In particular there is some evidence in the study that SCA may have contributed to facilitating mutual accommodations and high levels of commitment to the partnering relationship. This is particularly significant, given the asymmetrical nature of the relationship between LeisureCo and their partners, which was evident from the early stages of the partnership. LeisureCo potentially represented a continuous source of large-scale work for their partners and subcontractors, which made them a very powerful player within the partnership. Indeed, one of the main concerns at the beginning of the intervention was whether the application of SCA would only help to legitimise LeisureCo's intentions rather than support genuine accommodations between the parties.

To summarize, the following evaluation themes regarding the SCA-based intervention were derived from the analysis: effective problem structuring process, highly participatory process; high supportability and ownership of workshop commitments; learning and mutual accommodations. Overall, the evidence suggests that the high level of commitment to the joint agreements reached by all the partners, and their subsequent implementation can be interpreted as indicative of the creation of shared understanding about both the issues affecting the LeisureCo partnership, and the steps needed to address them.

\section{Discussion}

Before we begin with the discussion of the experience, it is worth noting that an arguable deficiency in the research process is that the intervention reported in this paper did not go through all the phases of the SCA-based method. It might be thought that this factor throws a shadow over the apparent support for the usefulness of PSMs in general, and SCA in particular, in the MOT context as evidenced in this research. Nevertheless, because of the time limitations which are characteristic of organisational life, a part of the method may often be all that a PSM facilitator is able to apply. Indeed, the potential for sections of methodologies to be used separately has already been recognised in the multi-methodology field [e.g. 28, 29]. 
Furthermore, the nature of the 'problematique' faced by LeisureCo and their partners in fact appears to have exhibited low levels of complexity and uncertainty, which is contrary to what is the normal sphere of application of SCA. Nevertheless, its application was regarded as successful by most of the participants on a whole range of attributes. This apparent contradiction can be resolved by providing higher specificity to the notion of complexity. For this purpose, it is possible to distinguish within multiorganisational settings both a behavioural and a structural aspect of complexity. Behavioural complexity can be thought of as derived from the presence of multiple organisations with multiple and (sometime) conflicting interests, with different power bases, and where uncertainties about guiding values (UV) and related agendas (UR) are present. Structural complexity, on the other hand, can be thought of as related to aspects such as the number of issues constituting the problematique, their interconnectedness and dynamic behaviour, and where strong uncertainties about the environment (UE) are present. Following this categorisation, the nature of the models developed in the three workshops and of the action plans which resulted from them suggest that the problematique of the LeisureCo partnership was characterised by high levels of behavioural complexity but low levels of structural complexity. Viewed in this light, the use of SCA can indeed be seen as appropriate for the problematique at hand.

Some of the intervention effects reported in this paper could have been due to the use of SCA with a particular form of MOT. That is, one which is formed to address a problem of common interest within the context of a collaboration framework such as a partnership. It has been argued that most if not all PSMs work best, or only, under situations in which there is an absence of fundamental conflict, or where there is a robust agreement upon mechanisms to negotiate or mediate such conflicts [see, for example, 30]. Such consensus situations are typical of organisational teams working collaboratively to alleviate a problem of mutual interest, which have traditionally been the subject of PSM interventions. Consensus situations can also be found in the multiorganizational context where: (1) the organizations each desire the performance of some joint task which can only be attained through cooperation; (2) the organizations supply services to each other in a mutually reciprocal way on which each of the participants depends; or, (3) there is a dominant organization, with which, for one reason or another, the other organizations wish to stay on good terms.

A multi-organisational collaboration process has the particular characteristic that the participant organisations have agreed to come together to resolve certain issues of mutual concern through dialogue rather than through action and reaction. Where none of conditions (1), (2), or (3) apply, various forms of negotiation may nevertheless occur. However, without the consensus assumptions (1), (2) or (3), there is no strong expectation that PSMs will be of assistance to the parties involved.

Partnerships are a particular case of multi-organisational collaboration in which the need to interact together is of a continuous or recurring kind. There is therefore some form of institutionalization of the relationship which, as already illustrated in the case of the LeisureCo partnership, includes formal or informal interface structures for interaction. It is not unreasonable to see the existence of partnership arrangements as an indication of a basic, if possibly circumscribed, compatibility of purpose. By extension it could thus be argued that MOTs operating within partnerships are in 
principle an appropriate setting for the use of PSMs: a setting of multiple stakeholders within a context of broad agreement which needs to be made operational.

It is worth considering whether some of the reported effects in the intervention could have been due to the choice of method or facilitator. However, it is never possible to be sure what would have happened if an alternative intervention approach to SCA had been used or a different facilitator had run the workshops. As Checkland [31] and Eden [32] argue, the characteristics of the problem situations for which PSMs have been developed make this kind of inquiry infeasible.

What are the implications of the intervention experience reported here for the wider use of PSMs in general, and SCA in particular, with MOTs? Generalisation will be discussed here from two related yet distinct standpoints. These are: generalisation from the LeisureCo teams to other partnership MOTs; and from SCA to PSMs.

The move toward partnerships within the UK construction industry represents a relatively recent trend. These partnerships are all different but with certain key characteristics in common:

- they are typically led by an individual construction client;

- issues of the facility in use and whole life cost are particularly salient for these clients, and these can only be addressed by having a wider set of priorities than the cost of the facility at project completion; and,

- apart from the client, membership of these partnerships usually involves main contractors and project management consultants, and a range of professional firms and specialist sub-contractors, including: architects, designers, quantity surveyors, and mechanical and electrical contractors.

The partnership from which the MOTs reported in this paper were drawn are thus in many ways characteristic of the many temporary multiple organisations that are set up to manage constructions projects [33, 34].

There is also the question of generalisation from SCA to other PSMs. The application of SCA, as has been seen, generated some positive effects. The use of SCA and its effectiveness can be understood in terms of facilitating 'conversations' [35] that generate a shared understanding and mutual accommodations among different stakeholder organisations facing a problem of mutual interest. These findings cannot be carried over unproblematically to the application of other PSMs in similar circumstances. PSMs are different yet they exhibit some similarities [1]. It is the similarities between SCA and other PSMs which give reason to be encouraged that they might also perform a useful role under these circumstances. So these findings are certainly a positive indication for the more general application of these methods. Provided that the problems of many partnership MOTs share the characteristics of high behavioural complexity and low structural complexity noted above, these findings seem to be potentially generalisable to other PSMs.

\section{Conclusions and further research}


Management scientists have been examining ways in which PSMs can support the work of management teams for many years. Most of this work has focused on teams working within the same organization. Increasingly, however, organizations are beginning to work together using MOTs as a means to operational their collaborative intentions. Such multi-organisational context presents challenges to the PSM facilitator due to the increased potential for conflict regarding multi-organisational issues, goals and values, the need to be seen as 'legitimate' by the MOT members, and the reliance on MOT members to negotiate the implementation of their joint agreements within their own constituencies. This paper has reported the implementation of a facilitated PSM intervention designed to address some of these challenges.

A key aspect of the intervention design was to set up a process by which the different construction actors would be able to re-negotiate their partnering relationship without resorting to their traditional adversarial stance. This was implemented through a transparent, highly participative and flexible problem structuring workshop process that contributed to achieve a balanced 'conversation' [35] among the stakeholders. Participants expressed the view that the work carried out with SCA helped them improve their understanding of the barriers and difficulties affecting both the partnership and the partners, and to have clearer views of their options for actions.

The experience as a whole confirms the importance of ensuring the legitimacy of the facilitator in a multi-organisational context. In the intervention reported here the facilitator, despite his association with LesiureCo, was known to and trusted by the other LeisureCo partners. In addition, care was taking in making sure that the MOT, rather than any individual participant organisation, was considered as the 'client' throughout the intervention. Having a trusted facilitator contributed to the need of developing a shorter, 'step-by-step' version of SCA because the facilitator, who had never used SCA before, felt the need to adapt SCA, largely avoiding its technical jargon and several of its techniques and tools. Producing a condensed versions of different methods seems contrary to the spirit of PSMs because they are complex methods developed to tackle complex problems. Nevertheless, easier routes to become an expert in PSMs [36] may be, as Westcombe et al [37] point out, the only way to ensure that the craft and skills of PSMs survive beyond their original developers.

Although it would be impossible to know whether the SCA process contributed to increase the boundary spanning competences on the workshop participants, their joint agreements reached members were indeed made legitimate and implemented within their constituencies. After each of the SCA workshops, participants knew what they wanted to do and had clear ideas about how to do it. Changes which took place among the partner organisations during the period of the intervention included the development of new communication interfaces for the partners (e.g. partners were to sit on project reviews and meetings other than those in which they were directly involved); the empowering of contractors in relation to LeisureCo's suppliers (e.g. by withholding payment of suppliers until the contractors were satisfied with their performance); a tighter definition of briefing documents (e.g. hotel bedroom models were developed and became available to LeisureCo partners); and the development of a new project management process for all partners with SCA as a key element. 
A follow-up conversation with LeisureCo's property development manager confirmed that, two years after the completion of the research, SCA continued to be used within the partnership as part of its standard project review procedures. SCA became part of the process manual which every project manager should follow, and LeisureCo extended its use from their four-star hotel projects where it was piloted during the research to their much larger program of renovations for their budget hotel chain.

Two potentially valuable possibilities for further research which have surfaced during this research can be formulated. First, the MOT studied in this paper is in many ways unique because it operated within a partnership context. Given the positive effects reported from the application of SCA with this particular type of collaboration, the possibility that SCA could have similar effects with other types of collaborations (within or outside construction) clearly deserves further investigation. Second, the intervention reported in this paper covered the use of SCA, a particular problem structuring method. SCA shares with other PSMs the purpose of enabling group interaction, encouraging participatory problem structuring and analysis, and generating shared understanding. Further work would be of value to investigate whether the findings established in this research extend to other PSMs used either in isolation or in combination with other methods.

\section{References}

1. Rosenhead, J. and J. Mingers, eds. Rational Analysis for a Problematic World Revisited: problem structuring methods for complexity, uncertainty and conflict. 2001, Wiley: Chichester.

2. Eden, C. and F. Ackerman, SODA: the principles, in Rational Analysis for a Problematic World Revisited: problem structuring methods for complexity, uncertainty and conflict, J. Rosenhead and J. Mingers, Editors. 2001, Wiley: Chichester. p. 21-41.

3. Checkland, P. and J. Scholes, Soft Systems Methodology in Action. 1990, Chichester: Wiley.

4. Friend, J. and A. Hickling, Planning Under Pressure: the strategic choice approach. 3rd ed. 2005: Elsevier.

5. Bryant, J., The Six Dilemmas of Collaboration. 2003, Chichester: Wiley.

6. Vennix, J., Group Model Building: facilitating team learning using System Dynamics. 1996, Chichester: Wiley.

7. Phillips, L., Decision Analysis for Group Decision Support, in Tackling Strategic Problems: the role of group decision support, C. Eden and J. Radford, Editors. 1990, Sage: London. p. 142-150.

8. Eden, C. and F. Ackermann, Strategy Making: the journey of strategic planning. 1998, London: Sage.

9. Gray, B., Collaborating: finding common ground for multiparty problems. 1989, San Francisco: Jossey-Bass.

10. Huxham, C., Facilitating Collaboration: issues in multi-organizational group decision support in voluntary, informal collaborative settings. The Journal of the Operational Research Society, 1991. 42(12): p. 1037-1045.

11. Huxham, C. and S. Vangen, Managing to Collaborate: the theory and practice of collaborative advantage. 2005, London: Routledge.

12. Taket, A. and L. White, Partnership and Participation: decision-making in the multi-agency setting. 2000, Chichester: Wiley. 
13. Ackermann, F., L.A. Franco, B. Gallupe, and M. Parent, Group Support Systems for Multi-organizational Collaboration: reflections on process and content. Group Decision and Negotiation, 2005. 14: p. 307-331.

14. Eden, C. and C. Huxham, The Negotiation of Purpose in Multi-organizational Collaborative Groups. The Journal of Management Studies, 2001. 38(3): p. 373-391.

15. Huxham, C., Group Decision Support for Collaboration, in Creating Collaborative Advantage, C. Huxham, Editor. 1996, Sage: London. p. 141151.

16. Friend, J., Searching for Appropriate Theory and Practice in Multiorganizational Fields. Journal of the Operational Research Society, 1993. 44(6): p. 585-598.

17. Friend, J. and A. Hickling, Planning Under Pressure: the strategic choice approach. 2nd ed. 1997, Oxford: Butterworth- Heinemann.

18. Williams, P., The Competent Boundary Spanner. Public Administration, 2002. 80(1): p. 103-124.

19. Franco, L.A., M. Cushman, and J. Rosenhead, Project Review and Learning in the UK Construction Industry: Embedding a Problem Structuring Method within a partnership context. European Journal of Operational Research, 2004. 152(3): p. 586-601.

20. Bryant, J., The Plot Thickens: understanding interaction through the metaphor opf drama. OMEGA, 1997. 25(3): p. 255-266.

21. White, L. and A. Taket, Beyond Appraisal: Partiipatory Appraisal of Needs and the Development of Action (PANDA) OMEGA, 1997. 25(5): p. 523-534.

22. Cushman, M., Action Research in the UK Construction Industry: the B-Hive Project, in IFIP WG 8.2 Working Conference on Realigning Research and Practice in Information Systems Development. 2001: Boise, Idaho.

23. Egan, J., Re-Thinking Construction: report of the Construction Industry Task Force. 1998, London: DETR.

24. Latham, M., Constructing the Team: final report of the government/industry review of procurement and contractual arrangements in the UK construction industry. 1994, London: HMSO.

25. Glaser, B. and A. Strauss, The Discovery of Grounded Theory. 1967, Chicago: Aldine.

26. Strauss, A. and J. Corbin, Basics of Qualitative Research: techniques and procedures for developing grounded theory. 1998, London: Sage.

27. Muhr, T., Atlas.ti: short user's manual. 1997, Berlin: Scientific Software Development.

28. Mingers, J. and A. Gill, eds. Multimethodology: the theory and practice of combining Management Science methodologies. 1997, Wiley: Chichester.

29. Mingers, J. and J. Brocklesby, Multimethodology: towards a framework for mixing methodologies. OMEGA, 1997. 25(5): p. 489-509.

30. Jackson, M., Systems Approaches to Management. 2000, New York: Kluwer.

31. Checkland, P., Systems Thinking, Systems Practice. 1981, Chichester: Wiley.

32. Eden, C., On Evaluating the Performance of "Wide-band" GDSS's. European Journal of Operational Research, 1995. 81(2): p. 302-311.

33. Cherns, A. and D. Bryant, Studying the Client's role in Construction Management. Construction Management and Economics, 1984. 2: p. 177-184.

34. Turner, J. and R. Muller, On the Nature of the Project as a Temporary Organization. International Journal of Project Management, 2003. 21: p. 1-8. 
35. Franco, L.A., Forms of Conversation and Problem Structuring Methods: a conceptual development. Journal of the Operational Research Society, 2006: p. 813-821.

36. Keys, P., On becoming expert in the use of problem structuring methods. Journal of the Operational Research Society, 2006. 57(7): p. 822-829.

37. Westcombe, M., L.A. Franco, and D. Shaw, Where Next for PSMs - $a$ grassroots revolution? Journal of the Operational Research Society, 2006. 57(7): p. 776-778. 
Table 1: Excerpts of interview data regarding participants' evaluation of SCA workshops

\begin{tabular}{|c|c|}
\hline $\begin{array}{l}\text { Transparency \& } \\
\text { problem structuring }\end{array}$ & $\begin{array}{l}\text { "From all responses you've lifted the various items, put them together, you said it came out like this, dumped it on us, we sat } \\
\text { down and we made a decision...I can find no problems with that.” (partner contractor) } \\
\text { "I think so because I think at least when the issues came out and they were up on the flipchart at least everybody concentrated on } \\
\text { that particular issue. Yes I think it did [work for me]. It kept it focused and kept people in unison. Yes.” (design subcontractor) } \\
\text { "...I think we needed a direction in terms of making it structured. I felt it was fine.” (property development manager) } \\
\text { "Coming with a list of items that everybody has put up together in effect, let's run through that and select as a group it's a good } \\
\text { way of doing it. It also gives the opportunity, by running through the list, things will stick in your head.” (partner contractor) } \\
\text { "I think those points which were brought up were all valid. I think that it certainly served to appreciate other people's difficulties } \\
\text { within the process. And I think those items - or those points - that were chosen to go forward with were valid.” (partner } \\
\text { consultant) } \\
\text { "I think that the recommendations that came forward were legitimately supported because everybody signed up to the issues we } \\
\text { needed to look at and everybody was a party to the information that was put forward. There wasn't anybody that was crying out } \\
\text { in disagreement anywhere." (partner contractor) } \\
\text { "I think is very difficult to know categorically you were right or wrong but I think you made a very good stab at the right } \\
\text { issues.” (property development manager”) } \\
\text { "The way that those issues were correlated into groups, was open. So I don't see that there was any great issue there” (partner } \\
\text { consultant) } \\
\text { "On the day? Well obviously the agenda and the areas of focus had been derived from feedback received from the } \\
\text { questionnaires. That struck me as fairly straightforward. I think it fell into about } 4 \text { chunks didn't it....Yeah. That seemed OK.” } \\
\text { (hotel operator) } \\
\text { "It was good in as much as the team were very much of one mind in terms of the things that went right and went wrong. And } \\
\text { were constructive about the things that had gone wrong and were keen to learn ways to improve those.” (design subcontractor) }\end{array}$ \\
\hline
\end{tabular}




\begin{tabular}{|c|c|}
\hline $\begin{array}{l}\text { Openness \& } \\
\text { participatory/ } \\
\text { adaptable/interactive } \\
\text { processes }\end{array}$ & $\begin{array}{l}\text { "When we did the brainstorming, what happens...someone said 'Oh I have an issue with directs', for example, and someone } \\
\text { says 'Oh yeah, they were...' and this sets other people to say “well he's right or he's wrong”...(partner consultant) } \\
\text { "The points made were valid and adequately discussed.” (partner consultant) } \\
\text { "Everybody had a through discussion or through sort of sticking their post-its, had an opportunity to put forward what they felt } \\
\text { were the critical and the key issues. So you had an opportunity to be either vocal or anonymous about what you were saying” } \\
\text { (partner contractor) } \\
\text { "I did appreciate that obviously you did change the direction it was going at HH to cater for the issues that we had, like the } \\
\text { snagging issues, because they were at the top of the agenda at the moment” (property development manager) } \\
\text { "Certainly in terms of the timing it was driven forward but these things need to be driven forward. I didn't feel compromised by } \\
\text { the way that it went.” (partner contractor) } \\
\text { "In terms of the results that we had I feel that they were sounder because they were discussed by all parties and all parties signed } \\
\text { up to them and jointly signed up to them as well.” (partner consultant) } \\
\text { "I think the workshop scenario works far better because it's less adversarial. You know, you can put your point forward...it } \\
\text { gives } \\
\text { people the ability to say, 'well look, looking back with hindsight (and not sitting } \\
\text { across the table) we probably could have done this better, and if we had the time we Iwould have done it a different way’” } \\
\text { (partner subcontractor) } \\
\text { "The meeting itself did, the way it was set up, I liked the format, the way it was set up. No tables. The open horseshoe which } \\
\text { cuts down on some of the barriers. I think that every party that was there was given the opportunity to air their views in one way } \\
\text { shape, form, or another.” (hotel operator) }\end{array}$ \\
\hline
\end{tabular}

